\title{
Credibilidad de la Iglesia y desafíos a la pastoral
}

Resulta evidente que la credibilidad de la Iglesia es un tema pastoral de enorme relevancia. Lo es no solo en un sentido práctico y concreto, sino también en lo que afecta a la actividad de la propia teología pastoral. La centralidad del tema y los desafíos que él trae consigo es lo que intentaremos abordar en los próximos puntos.

\section{PLANTEAMIENTO DEL TEMA}

La experiencia cristiana fundamental respecto a la tarea de la Iglesia se ha expresado permanentemente de múltiples maneras, como por ejemplo: "La Iglesia tiene como misión primordial la de llevar a todos y a cada uno al encuentro vital con Jesucristo" (1). Así queda expresado claramente tanto la centralidad de la relación a Jesucristo como el lugar que ocupa la Iglesia en esa relación.

Lo importante para el cristiano es la fe en Jesús. En el seguimiento de Jesús alcanza nuestra relación con Él toda su madurez y plenitud, y se nos hace patente que la fe en último término es entrega a una persona (2).

Pero a esa fe llegamos y en esa fe crecemos "eclesialmente". Lo sabemos y lo experimentamos cotidianamente: la Iglesia es fuente, apoyo y norma de lo que creemos. En este sentido creemos en la Iglesia, dentro de la Iglesia, como Iglesia (3). La Iglesia es esencialmente una comunidad de creyentes y la fe es una realidad eclesial (4).

(1) Conferencia Episcopal de Chile, Orientaciones Pastorales 2001-2005, $\mathrm{N}^{\mathrm{o}} 160$.

(2) En este sentido escribe Hans Küng: "La fe, en sentido último, pleno y radical, en que no puede ya distinguirse adecuadamente de la caridad, es un obrar personal, referido a un objeto (sujeto) personal. En la fe no se trata nunca, a la postre, de meros objetos, proposiciones y dogmas, sino de una entrega, de la donación de una persona a otra. Lo que en todo acto de fe aparece como decisivo es la persona, a cuya palabra se presta asentimiento (Tomás de Aquino, ST II-II, q. 11, a. 1). Ahora bien, solo respecto de Dios es posible una entrega personal, radical, absoluta e irrevocable a todo evento, solo en Él puede creer el hombre en el sentido radical más pleno de la palabra". H. Küng, La Iglesia, Barcelona 1968, pg. 45.

(3) Cfr. explicaciones en: Catecismo de la Iglesia Católica No 748 a No 975.

(4) Küng lo explica así: "Ahora bien, que creemos la (realidad de la) Iglesia quiere decir: 
La Iglesia tiene, entonces, la tarea de conducir a las personas al encuentro con Jesús, de modo de despertar y hacer crecer en ellos la adhesión y el seguimiento propios de la fe. Hemos encontrado esta realidad formulada en muchas páginas de los textos conciliares del Vaticano II, al explicarnos la Iglesia como "sacramento", "signo e instrumento" de salvación.

"Ese pueblo mesiánico tiene por Cabeza a Cristo, que fue entregado por nuestros pecados y resucitó para nuestra salvación (Rom 4, 25), y habiendo conseguido un nombre que está sobre todo nombre, reina ahora gloriosamente en los cielos. Tiene por estado la dignidad y libertad de los hijos de Dios, en cuyos corazones habita el Espíritu Santo como en un templo. Tiene por ley el mandato nuevo de amar como el mismo Cristo nos amó (cf. Jn 13, 34). Tiene últimamente como fin la dilatación del Reino de Dios, incoado por el mismo Dios en la tierra, hasta que sea consumado también por Él mismo al fin de los tiempos, cuando se manifieste Cristo, nuestra vida (cf. Col 3, 4), y la misma criatura será libertada de la servidumbre de la corrupción para participar en la libertad de los hijos de Dios (Rom 8, 21). Aquel pueblo mesiánico, por tanto, aunque actualmente no contenga a todos los hombres, y muchas veces aparezca como una pequeña grey es, sin embargo, el germen firmísimo de unidad, de esperanza y de salvación para todo el género humano. Constituido por Cristo en orden a la comunión de vida, de caridad y de verdad, es empleado también por Él como instrumento de la redención universal y es enviado a todo el mundo como luz del mundo y sal de la tierra (cf. Mt 5, 13-16) (5)".

En la literatura en torno al Concilio Vaticano II y en los textos de Teología Pastoral se ha repetido y profundizado frecuentemente este carácter de "signo e instrumento" que es propio de la Iglesia. Lo encontramos sintéticamente explicado por Casiano Floristán:

"El texto conciliar habla de "signo e instrumento". Signo es una realidad sensible que remite a otra distinta, con la que está unida mediante algo objetivo, no convencional. La realidad a que nos remite el símbolo es el misterio de Dios. Cuando la experiencia simbólica es religiosa, la realidad percibida y sentida es divina. La relación entre lo visible (el significante) y lo invisible (el significado) se puede realizar en el ser, la significación y la causalidad. Jesucristo es sacramento en el ser; la Iglesia es sacramento primordial en la significación y

1. Que la Iglesia se constituye, por gracia de Dios, mediante la fe; una comunidad que no cree, no es Iglesia. La Iglesia no existe en sí misma, sino en los hombres creyentes concretos. Como no hay un pueblo sin hombres ni un cuerpo sin miembros, así tampoco Iglesia sin creyentes. La Iglesia no nace simplemente porque Dios la crea, sino porque los hombres que han de formar la Iglesia toman la decisión que se les pide, la decisión radical por Dios y por su reino. Esta decisión es la fe.

2. Que la fe, por la gracia de Dios, se constituye por la Iglesia. Dios llama a cada uno a la fe; pero sin la comunidad que cree, el individuo no llega a la fe. Tampoco la fe existe en sí misma, sino en los hombres concretos creyentes..." H. Küng, op. cit. pg. 47s 
la causalidad. La gracia de Dios es significada e instrumentalmente causada por la Iglesia como símbolo o sacramento (6)".

Así entendemos que la Iglesia no existe para sí misma "sino para el mundo, con el fin de transformarlo en reino de Dios" (7). Y la pregunta que aquí nos ocupa es si la Iglesia está realizando bien la labor que hemos descrito: ¿es ella, en nuestro tiempo y en este lugar, un buen "signo e instrumento" de salvación?

La pregunta no es nueva. Si bien es tan antigua como la Iglesia misma, ha sido la pregunta formal que ha tenido la Teología Pastoral en los últimos siglos, y que con toda insistencia fue planteada en el Vaticano II. Las definiciones propias del sentido y de la actividad de la Teología Pastoral hablan de una "eclesiología existencial", donde la pregunta fundamental es aquella respecto a la realización de la misión de la Iglesia en el hic et nunc de la historia (8).

Aquí surge la importancia de la credibilidad de la Iglesia. Ella debe ser capaz de manifestar el misterio que porta a lo largo de la historia. Hoy nos encontramos con una fuerte crítica a la Iglesia justamente respecto a este aspecto central de su misión. En los próximos párrafos trataremos de distinguir los elementos incluidos en la crítica y precisar las preguntas que ello nos trae.

\section{LA MIRADA DEL HOMBRE ACTUAL A LA IGLESIA}

Un primer paso para abordar la pregunta sobre la credibilidad de la Iglesia es ponernos en el lugar del hombre actual y tratar de describir la mirada que él dirige a la Iglesia. Esto es relevante no solo del punto de vista metódico, sino también como encargo explícito:

"Para realizar este cometido (continuar la obra del mismo Cristo) pesa sobre la Iglesia el deber permanente de escrutar a fondo los signos de los tiempos e interpretarlos a la luz del Evangelio, de forma que, acomodándose a cada generación, pueda la Iglesia responder a los perennes interrogantes humanos sobre el sentido de la vida presente y futura, y sobre la mutua relación entre una y otra. Es necesario, por tanto, conocer y comprender el mundo en que vivimos y sus esperanzas, sus aspiraciones, su modo de ser, frecuentemente dramático" (9).

La última frase nos entrega una orientación para nuestra opción en orden a ponernos en el lugar del hombre actual y comprender la mirada que él dirige a la Iglesia. Al buscar en la literatura del presente aportes para este tema, nos encontramos con poco material. En general, los textos de Iglesia plantean los deseos de esta,

(6) C. Floristán, La Iglesia, comunidad de creyentes. Salamanca, 1999. Pg. $171 \mathrm{s.}$

(7) Floristán, op. cit., pg. 172.

(8) Cfr. H. Schuster, "Ser y quehacer de la teología pastoral”. En: Concilium, Revista internacional de Teología 3 (Marzo 1965). Pgs. 5-16.

(9) GS No 4 . 
las tareas propias y las metas que la guían, o bien tratan de hacer un análisis objetivo de la situación, pero sin detenerse demasiado en la pregunta acerca de las dudas, cuestionamientos o esperanzas con que el hombre de nuestro tiempo enfrenta a la Iglesia católica. En esta línea es interesante lo que se lee en distintas páginas de las últimas orientaciones pastorales de la Iglesia en Chile:

"Hay otros dolores que marcan nuestra historia y que han involucrado a los hijos de la Iglesia, como son, por ejemplo, las injusticias causadas a los pueblos originarios, las violaciones en diversas épocas de derechos humanos que han desangrado y dividido al país, la falta de tolerancia religiosa de fines del siglo diecinueve, las convulsiones políticas de la segunda mitad del siglo pasado y el antitestimonio en la caridad de laicos y religiosos, diáconos, sacerdotes y obispos...

Nos preocupa también la falta de espíritu misionero, la dificultad para trabajar con los laicos y las actitudes autoritarias que frenan su efectiva participación en la Iglesia. También reconocemos la falta de creatividad en el diálogo ecuménico e interreligioso, la poca transparencia en las finanzas de las instituciones eclesiales, las divisiones que, con razón, escandalizan a muchos en nuestras comunidades" (10).

Estas líneas nos transmiten algo de esa mirada con la que los hombres de nuestro tiempo observan a la Iglesia católica (11). Tratemos ahora de aproximarnos aún más a esa mirada describiendo en general algunos de sus rasgos principales, sin detenernos en los contenidos que trataremos de abordar más adelante:

Creemos que el hombre actual mira con preguntas permanentes, "eternas". Es, además, un hombre acostumbrado a preguntarlo todo. Le interesa especialmente la relación de todo lo que lo rodea con él mismo, lo que a él le atañe. Y también mira con interrogantes que hoy se han hecho agudas, urgentes. Tal vez eternas, pero hoy más fuertes, más dolorosas, más importantes. Interrogantes que manifiestan novedad.

En su mirada hay una marca cultural. Distinta según lugares, momentos, edades, grupos. Estamos en un momento culturalmente no homogéneo, de interacción cultural y de cambios. Constatamos en su mirada preguntas que vienen de la modernidad, de la postilustración, de la postmodernidad.

También hay aspectos no racionales y no conscientes. El hombre que hoy mira a la Iglesia está marcado por búsquedas que incluso él no puede expresar claramente o conscientemente. Necesita respuestas, caminos, esperanza, vida. Encontrar sentido a su existencia particular.

Su mirada está cargada emocionalmente por experiencias anteriores. Mira con desconfianza, sobre todo en relación a ciertos temas. Ha aprendido por experiencia también a confiar en algunos ámbitos. Por eso también quiere conservar lo que ha descubierto que le da vida. Quiere volver a encontrarlo y desarrollarlo.

(10) Conferencia Episcopal de Chile, Orientaciones Pastorales 2001-2005, No 79 s.

(11) También lo reconocemos así en textos como el Documento de Puebla o escritos de Juan Pablo II, donde se describe a veces lo que los hombres de nuestro tiempo sienten y piensan de la Iglesia católica. 


\section{Algo sobre el Chile actual}

Antes de precisar mejor los desafíos que la credibilidad de la Iglesia presenta a la pastoral, conviene dedicar algunos párrafos a la realidad de la Iglesia en Chile. Sin mayores pretensiones nos mueve para ello la importancia de destacar que este tema deberá tener siempre un connotación local. De hecho, la Iglesia puede realizar mejor o peor su misión en un lugar y un momento de la historia, de modo que resulta inadecuado abarcar el mundo entero y todos los ámbitos posibles simultáneamente. La realización concreta de la misión universal y permanente de la Iglesia debe ser estudiada necesariamente en momentos y lugares particulares, pues una básica verdad histórica nos señala lo inconveniente de universalizar juicios particulares. Lo dice Peter Berger en un típico lenguaje sociológico:

“...Los cristianos que se proponen acomodar la fe al mundo moderno deberán preguntarse a sí mismos a qué sector de ese mundo intentan dirigirse. Es muy probable que cualquier aggiornamento que realicen incluya a algunos y excluya a otros. Y si el aggiornamento se emprende con la elite cultural como objetivo, es importante tener en cuenta que las creencias de este grupo en particular son las más volubles de todas" (12).

Teniendo en cuenta entonces estas advertencias acerca de generalizaciones indebidas, queremos planteamos la pregunta de la credibilidad de la Iglesia en el Chile actual.

Chile sin duda es una sociedad en gran cambio. Lo constatamos permanentemente y es objeto de estudios que se publican a diario en los medios de comunicación (13). Para detectar algunas realidades chilenas acerca de la Iglesia y su credibilidad queremos recoger aquí una investigación sobre la opinión pública realizada en diciembre de 2002.

Al indagar acerca del así llamado "proceso de secularización" se establecen preguntas respecto a la identificación con la Iglesia católica, la asistencia a misa y la autodefinición como practicante. Los resultados indican que la adhesión a la Iglesia católica ha fluctuado en los últimos 15 años entre el $75 \%$ y el $70 \%$. El "paulatino descenso", sin embargo, no constituye una variación de orden mayor.

(12) Peter L. Berger, Una gloria lejana. La búsqueda de la fe en época de credulidad. Barcelona 1994. Pg. $21 \mathrm{~s}$.

(13) Un ejemplo de estos cambios ocurre en relación a los hogares y las familias. Leemos: Para obtener la fotografía real de la mutación ocurrida en los hogares chilenos, basta solo algunas cifras. Las mujeres tienen un promedio de 2,2 hijos en su vida. Antes, en los años 30 ó 40 se embarazaban entre 10 y 12 veces en su vida y en la década del 50 daban a luz en promedio 4,6 hijos. Hoy en Chile, 473.743 personas viven absolutamente solas (un poco más del 11\% de la población), más del doble que lo que mostró el Censo de 1992. En un tercio de los hogares chilenos $(31,5 \%)$ son las mujeres... las que sostienen la casa, versus un $25,3 \%$ que lo hacía hace 10 años... La tradición de aquellos hogares extendidos con padre, madre y parientes viviendo bajo el mismo techo, representa solamente el 23\% de las familias... En 2001 se inscribieron 64.153 matrimonios. Si se compara con que en 1961, cuando Chile tenía una población de cerca de 8 millones de personas -la mitad de la actual- se efectuaron 57.394 matrimonios, la cifra es por lo menos abismante. También las nulidades aumentaron un 104\% en el período 1980-1998". Revista El Sábado, diario El Mercurio, 9 de mayo 2003, pg. 23 s. 
La asistencia a misa se ubica actualmente en el 23\% (suma de las respuestas "más de una vez por semana" y "una vez por semana") y no ha experimentado cambio en los últimos 6 años.

En cuanto al grado de religiosidad de los chilenos, en noviembre de 1987 el $35 \%$ se consideró "muy practicante" o "practicante". Quince años después, en diciembre de 2002, un 33\% dice ser "muy practicante" o "practicante".

En contraste con la tendencia relativamente estable mostrada hasta aquí, las preguntas que de alguna manera tocan la credibilidad de la Iglesia experimentan otros resultados.

Ante la pregunta: "Le voy a decir el nombre de algunas instituciones. ¿Podría decirme cuánta confianza tiene Ud. en cada una de ellas: mucha, bastante, poca o ninguna confianza?" La respuesta positiva ("mucha" y "bastante confianza") tuvo en junio de 1990 para la Iglesia católica un $76 \%$ y en julio de 2002 un 52\%. A raíz de los problemas de fines de ese año, la respuesta cayó en diciembre de 2002 al 36\%. Si tomamos el conjunto, hay un deterioro de 40 puntos en la confianza de la gente en los últimos 12 años. A modo de comparación, en ese mismo lapso la confianza en Carabineros descendió del 59\% al $47 \%$ y la confianza en el Poder Judicial descendió del $44 \%$ al $14 \%$, lo que muestra una tendencia generalizada a distanciarse de las instituciones políticas y sociales, aunque acentuada frente a la Iglesia católica.

Algo semejante ocurre en la pregunta respecto a los obispos católicos. Al indagar la confianza en las elites políticas y sociales, se pregunta: "Para la solución de los problemas nacionales, Ud. tiene mucha confianza, bastante confianza, poca confianza en...". La suma de "mucha confianza" y "bastante confianza" para los obispos fue en diciembre de 1988 de $58 \%$ y en diciembre de 2002 de $27 \%$. También aquí se nota especialmente la influencia de los problemas de fin del año 2002. Comparando, durante ese período la confianza en Carabineros descendió del $48 \%$ al $47 \%$ y la confianza en los jueces descendió del $48 \%$ al $12 \%$.

Constatamos así una interesante diferencia entre los índices de adhesión a la Iglesia, que permanecen prácticamente iguales, y la confianza en ella y sus pastores, que desciende significativamente en los últimos años. Hay una pregunta abierta si esta creciente brecha no terminará afectando la adhesión. También se constata algo semejante a la pregunta puntual: “¿Está Ud. de acuerdo..., con las actuales orientaciones que le dan el Cardenal y los Obispos a la Iglesia?", ya que aparecen con respuesta positiva un $35 \%$ de los encuestados, lo que corresponde a la cifra de practicantes. Interesantemente los índices indican que los menos críticos son los jóvenes y los pobres. La relación de la Iglesia con los jóvenes puede ser estudiada más en detalle, pero las cifras de esta investigación no constatan un alejamiento mayor en los sectores jóvenes que en los otros sectores de la población.

\section{DESAFÍOS A LA PASTORAL}

La credibilidad de la Iglesia presenta desafíos a la pastoral. Son preguntas dirigidas a la vida y a la acción de la Iglesia, es decir, a la actualización del Evangelio en el aquí y ahora de nuestra historia, a la acción evangelizadora de las personas y de las comunidades. En otras ponencias se ha abordado ya temas particulares 
como el uso del poder, la sexualidad, la confiabilidad de la Escritura, etc. Trataremos de percibir ahora el conjunto de los desafíos a los cuales se enfrenta la Iglesia desde el punto de vista de su credibilidad.

Para ordenar los temas nos apoyaremos en una división cuatripartita de la acción pastoral que se ha hecho clásica en los últimos años (14). Queremos sintetizar la realidad de estos ámbitos pastorales en relación a cuatro palabras típicas: comunidad, comunicación, misión y celebración. En cada uno de ellos está planteada la pregunta acerca de lo adecuado de la acción de la Iglesia, debiendo ella responder por su credibilidad. Es importante distinguir no solo los aspectos deficitarios, sino los posibles aciertos y las oportunidades que ofrecen variados caminos hacia adelante.

\section{En relación a la comunidad eclesial}

La comunidad eclesial ha vuelto a reconocerse marcada esencialmente por su vocación a la comunión. Este tema, decididamente evangélico, volvió a recuperarse con fuerza en el entorno del Concilio Vaticano II. Influye en ello muchísimo la Encíclica Mystici Corporis de Pío XII, así como también el avance en los estudios bíblicos, el movimiento litúrgico y las aspiraciones ecuménicas. En realidad se trata de un desarrollo que tiene raíces culturales más amplias. Se nota esto, por ejemplo, en algunos vínculos al contexto filosófico: "Las corrientes filosóficas personalistas, y en especial el personalismo cristiano de Mounier, habían puesto de relieve en la década de los cincuenta la importancia de la comunión en comparación con el concepto de sociedad. En los primeros capítulos de Lumen gentium, la Iglesia es entendida en clave de comunión más que bajo el concepto tridentino (o belarmiano) de sociedad" (15).

Esta renovación de la Iglesia "hacia adentro" provocó mucha alegría y despertó muchas expectativas. Sin embargo, hay balances críticos acerca del desarrollo de la Iglesia en los siguientes años. Se critica, por ejemplo, la evolución del tema ecuménico, la incorporación del laico en la vida y las tareas de la Iglesia, la colegialidad episcopal, el ejercicio de la autoridad y de la disciplina, la falta de acogimiento al que llega "desde fuera" (16).

(14) Al respecto explica C. Floristán: "Recientemente E. Alberich señala cuatro formas fundamentales de presencia eclesial: diaconía, koinonía, kerigma y liturgia. De este modo -afirma-, la Iglesia se presenta en el mundo como el lugar por excelencia del servicio, de la fraternidad, del significado, de la fiesta... D. Borobio indica así mismo cuatro dimensiones de la misión, al analizar el puesto de la liturgia en la acción de la Iglesia: dimensión de la palabra o profética, la dimensión de culto o litúrgica, la dimensión de la caridad o real y la dimensión de comunión o directiva". C. Floristán, Teología Práctica. Teoría y praxis de la acción pastoral. Salamanca 1991. Pg. 223. Allí se encuentran las referencias y las citas.

(15) C. Floristán, op. cit., pg. 575 s.

(16) Bajo el título un tanto trágico de "Credibilidad desperdiciada" una serie de teólogos alemanes (Greinacher, Rahner, Metz, Ratzinger, etc.) escriben un balance a 25 años del Concilio. Heinrich Fries expresa: "25 años después del Concilio la situación ha cambiado drásticamente. La Iglesia se ha transformado en un problema tanto para el mundo y la sociedad, como para los miembros de ella misma". H. Fries, Imageverlust, en: Markus Fels (Hrgr.), Träumen muss erlaubt sein. Zürich 1992. Pg. 48. 
El tema de la comunión vuelve a ser en este tiempo una preocupación pastoral aguda. Lo notamos especialmente en las indicaciones generales de Juan Pablo II (Novo millennio ineunte) y en las orientaciones particulares de la Iglesia local (Carta pastoral sobre la espiritualidad de la comunión, del Cardenal Errázuriz). Esta preocupación corresponde a una necesidad: la Iglesia tiene que transformarse en un lugar donde se viva más verdaderamente el mandamiento del amor. Sobre esto volveremos nuevamente al final de esta ponencia.

La falta de credibilidad no solo está referida al "alma" de la Iglesia que es el amor, sino, por eso mismo, a expresiones concretas de su realidad entre los hombres. Ya hemos señalado aspectos estadísticos del deterioro de la confianza en la institución (17). Y ellos están asociados a la crítica a las personas, por ejemplo: obispos, sacerdotes y también laicos representativos.

\section{En relación a la comunicación}

Bajo este título queremos resumir distintos temas que afectan la credibilidad de la Iglesia. El primero se refiere a la comunicación de la Palabra, como presencia del mismo Cristo que se comunica. Sin entrar en la discusión de lo relativo a la Escritura (presentado en una ponencia anterior), podemos detectar dos campos de problemas y desafíos: la predicación y la profecía. En relación a la predicación hay una queja generalizada de falta de capacidad de transmitir adecuadamente los contenidos. Las prédicas en sentido estricto y las explicaciones catequéticas en sentido amplio, carecen de habilidad comunicativa en un mundo que ha hecho de esto un punto clave de la articulación social. Creemos no exagerar si afirmamos que en muchos ámbitos la Iglesia se ha ido quedando muda. En relación a la profecía se constata una cierta incapacidad de interpretar los signos de los tiempos. Este es un tema que toca no solo la apertura al Espíritu de Dios y sus inspiraciones, sino también al método pastoral y a sus definiciones teóricas. La falta de propuesta profética hace a la Iglesia un tanto pusilánime, con inseguridades, con miedo a equivocarse y deseo exagerado de adaptarse. Recordemos la propuesta de pobreza de parte de San Francisco, en el contexto de una Italia cuyas ciudades se iban haciendo ricas por el comercio y de una familia acomodada de su época. Chesterton escribe al respecto: un tiempo tiene no los santos que quiere, sino los que necesita. Hay en muchos un anhelo de recibir de parte de la Iglesia indicaciones llenas de espíritu y vida.

Al ámbito de la comunicación pertenece también la teología, el discurso teológico y sus argumentaciones. Sobre esto ya se ha largamente discutido en este seminario con ocasión de otras ponencias. Queremos aquí solamente recordar lo expresado en relación al defecto pastoral de recurrir exageradamente al argumento de autoridad.

(17) Este tema lo ha abordado ya el Prof. Juan Noemi en su ponencia y ha buscado las razones que pueden explicar el fenómeno. 


\section{En relación a la misión}

En este ámbito queremos detenernos en la actividad de la Iglesia "hacia afuera". En realidad se trata del anuncio de Cristo a todos los hombres y de la generación de condiciones para que todo hombre acceda a la fe. ¿Qué hace convincente el mensaje de la Iglesia? A lo largo de este seminario hemos tocado distintos aspectos que pueden llevar a la Iglesia a ser "creíble": las afirmaciones y su argumentación, la institución y su espíritu, las personas, etc. Queremos detenernos aquí en la importancia pastoral de dos aspectos confluyentes: la oferta de sentido y el conjunto del modo de vivir.

Hay una pregunta eterna en el hombre respecto al sentido de su existencia. Ya terminológicamente se emplea más la forma "encontrar o descubrir el sentido" que "dar sentido", indicando que existe la intuición fundamental de que la búsqueda no es vana, sino que está encaminada a una respuesta. Cristo ofrece luz para percibir no solo la existencia de la realidad, sino para descubrirla como un don, como la donación de un tú personal y benevolente. Tanto las relaciones que Él puede establecer con todo (Dios, personas, cosas, etc.), como la historia que se va generando progresivamente en su vida, se hacen transparentes de un designio de bondad y de vida para Él. Se experimenta hijo. Y hermano. En el claroscuro de su realidad concreta y contingente, aparece la vocación a la vida plena, llenando su existencia, a veces dichosa, a veces amenazada, de alegría en la esperanza. La pregunta pastoral que queremos plantear es cuán real es esta oferta de sentido en nuestras comunidades cristianas y hacia todos los hombres. En este contexto se plantean, por ejemplo, acusaciones de ideologización.

En cuanto al conjunto del modo de vivir, la credibilidad de la Iglesia presenta la pregunta acerca de la coherencia. Evidentemente nadie puede exigir que un cristiano viva enteramente el Evangelio de Jesús. Hay normalmente una distancia entre lo que se vive y lo que se anuncia. (Una antigua expresión de esto es el dicho: anuncio el Evangelio que me acusa). Pero sí se puede esperar del cristiano y del evangelizador un esfuerzo constante y consistente por encarnar en su vida el Evangelio. Encontramos a menudo, especialmente en jóvenes, la demanda de coherencia en las personas y en la comunidad eclesial. No se puede descalificar este tema como "un típico problema adolescente". Creemos que lo que está detrás es la búsqueda de una manera de vivir, como algo integral, íntegro. Es preciso comunicar la manera de vivir de Jesús. Esto justamente protege frente a una de las manifestaciones de la ideologización: transformar el cristianismo en una doctrina o una explicación de la realidad. El cristianismo, en cuanto a comunicación de Vida, ha de transmitir el modo de vivir de Cristo Jesús. En la existencia de cada uno hay ciertamente momentos oscuros y en las personas hay aspectos negativos; sin embargo, la validez de esta forma de vivir permite creer también cuando está oscuro y cuando nos enfrentamos a lo negativo. La pregunta pastoral es, entonces, cuán coherentemente bueno (cuán convincente) es el conjunto de nuestro modo de vivir.

En este contexto, Paul Zulehner presenta algunas palabras que para él son claves en el ofrecimiento que la Iglesia hace al mundo para transmitirle la realidad de Jesús. Él se detiene en: (1) Paz (el bíblico shalom); (2) Libertad y Liberación; (3) 
Esperanza; (4) Vida; (5) Salud, Sanación, Salvación; (6) Comunión y Pueblo (18). Todas ellas, que Zulehner llama "criterios", indican justamente en el sentido que hemos descrito en los párrafos anteriores.

\section{En relación a la celebración}

Este tema es muy amplio y pastoralmente de mucha relevancia. Comprende todo el campo de la liturgia y los sacramentos, así como también todo tipo de signos (ordinarios y extraordinarios) de la presencia de Cristo y de la transmisión de su vida. Queremos destacar, sin embargo, un aspecto particular. Se refiere a lo que en la literatura se denomina "fiesta". Sostener que la celebración es una fiesta, supone comprender esta como una vivencia significativa y constituyente de la comunidad cristiana (Josef Pieper sostenía que fiesta es cuando el amor se alegra). "Vivencia" significa, como realidad pastoral, una calidad de experiencia, donde la persona es incorporada como totalidad a un acontecimiento común, integrando sus dimensiones cognitivas y emocionales, activas y receptivas, de modo que queda captado lo más profundo de su núcleo personal, de su "corazón" en un sentido bíblico (19). En este sentido se puede afirmar que muchas veces la Iglesia no es "convincente" porque no toca el corazón del hombre. Un extendido intelectualismo pone mayor énfasis en lo doctrinal descuidando la captación de esferas afectivas o instintivas, y desentendiéndose de la necesaria capacidad pedagógica para tocar la vida del hombre y desarrollarla conforme a su naturaleza.

\section{A MODO DE CONCLUSIÓN}

Para terminar estas reflexiones, necesariamente de carácter provisorio, quiero plantear tres tesis de orden pastoral frente al tema de la credibilidad de la Iglesia.

\section{La Iglesia pierde credibilidad cuando no es lugar de misericordia}

La irrupción del reino en Cristo puede ser comprendida como la oferta gratuita y definitiva de la misericordia de Dios, que invita a una decisión radical por incorporarse como hijo y hermano a esa dinámica de amor (20). Se podría decir que ese es el "tesoro" que llevamos en un "vaso de barro". Pero ¿cuánto experimenta el hombre actual en la Iglesia la misericordia gratuita y definitiva de Dios?

El "amor hasta el extremo" con que el Evangelio de San Juan abre los largos capítulos sobre la última cena de Jesús con sus "amigos", debería ser la carta de presentación de la Iglesia frente a un mundo herido por las soledades y los desamparos del fin de la modernidad. El mandamiento nuevo es el encargo de toda eucaristía, de todo sacramento, de toda vivencia y acción eclesial.

(18) Cfr. Paul M. Zulehner, Pastoraltheologie. Band 1. Düsseldorf, 1989. Pgs. 64-96.

(19) Cfr. J. Kentenich, Dass neue Menschen werden. Treveris, 1971. Pgs. 39-55.

(20) Cfr. J. A. Ramos, Teología pastoral, Madrid 1995. Pg. 24 s. 
El amor proclamado y vivido - "mirad como se aman"- se convierte en una invitación a creer, a abrir las puertas a una realidad nueva que "solo se puede creer" pero que es gozosa y plena, capaz de otorgar sentido y animar en la esperanza. Más allá de los defectos, errores y pecados de los cristianos (pueblo y pastores), ha de llegar a todos a través de la Iglesia el amor de Dios manifestado en Cristo Jesús. Es la atracción que producen en su entorno figuras marcantes como la Madre Teresa de Calcuta.

Ese mismo amor encuentra su plenitud en el ofrecimiento de toda la vida, de todo lo que se piensa, hace o sufre, por los hermanos. A la antigua pregunta: cómo se puede colaborar a la salvación de los hermanos, respondía la doctrina del mérito: entregándose por entero -en Jesús- por ellos, hasta la cruz y la muerte si es necesario. Nadie tiene mayor amor...

Por eso, tanto más dolorosamente resuena la crítica de que la Iglesia ha olvidado la misericordia. Se presenta, por ejemplo, con dolor, en los casos más difíciles de la pastoral matrimonial, pero a veces se refiere también al ambiente interno de la Iglesia o a las cosas que parece importarle de la vida pública. Algunos discursos se perciben afectados por un cierto moralismo, que parece sostenerse más bien sobre la autoridad del que quiere disciplinar y ordenar conductas. La falta de transparencia hacia el misterio que lleva en sí, puede volcar a los cristianos a una cierta autorreferencia.

A esto se ha estado respondiendo con la acentuación de la temática de la comunión, del amor y del carácter familiar de la Iglesia. Hans Urs von Balthasar aporta, en este contexto, una reflexión sobre el carácter femenino de la Iglesia:

"La Iglesia postconciliar ha perdido en gran medida sus rasgos místicos; ella es una Iglesia de permanentes reuniones, organizaciones, consejos, congresos, sínodos, comisiones, academias, partidos, grupos de presión, funciones, estructuras y cambios estructurales, experimentos sociológicos, estadísticas: más que nunca una Iglesia de varones (Männer-Kirche), o bien una organización asexuada, en la cual la mujer solo podrá conquistar un lugar si está dispuesta a ser ella lo mismo...

¿No dominarán estos inventos típicamente masculinos y abstractos todos los ámbitos porque la femineidad más interior de la Iglesia, el carácter mariano, se ha perdido?" (21).

\section{La Iglesia pierde credibilidad cuando no respeta la dignidad}

La valoración de la persona y de su carácter único tiene honda raíz bíblica y es parte constitutiva de la enseñanza y la acción de Cristo. Pero en estos tiempos posee particular importancia. Se podría ver aquí una de las huellas más hermosas de la modernidad: el descubrimiento y la acentuación de la dignidad de la persona, de su conciencia, de sus capacidades. Más allá de los errores y pecados que pueda señalarse, hay algo profundamente evangélico en el reconocimiento de que cada ser huma-

(21) H. U. von Balthasar, Klarstellungen. Freiburg 1971. Pg. 70. 
no posee un valor inmenso -“infinito" suele alguno decir al ungir en el bautismo- y merece todo respeto.

Pero no se trata solo de la dignidad en general. Se trata de la particularidad de cada ser y comunidad, se trata de su singularidad, de su originalidad. Incorporándose al Dios que ama a cada uno, hemos de valorar y promover la propia identidad de cada cual, lo que tiene como fundamento la actitud del respeto pero va mucho más lejos. Es la dedicación amorosa y responsable a la vida de otros, a su crecimiento y a su camino hacia una plenitud compartida y solidaria. El surgimiento de voces distintas, de aportes distintos, traerá necesariamente cuotas de tensión o de desorden, pero hemos de aprender a vivir y conducir serenamente con alegría en la diversidad. La Iglesia ha de reconocerse en la imagen del jardín o de la sinfonía, donde las particularidades son reconocidas como dones que vienen de la mano del Dios vivo y hacen la vida (la creación, la Iglesia) más hermosa y llena de sentido. Como acción del Espíritu vemos surgir para esto una renovada teología de los carismas y una voluntad de diálogo con el tiempo. En todo caso, ante el impulso violento y agresivo de la manipulación y la masificación, la Iglesia puede ser un espacio de personalización y respeto (22)

\section{La Iglesia pierde credibilidad cuando no tiene sentido pedagógico}

Por "sentido pedagógico" entendemos aquí la percepción de los procesos vitales, de los desarrollos de los organismos vivos. Los dos puntos anteriores adquieren, en relación a esto, una nueva importancia: por una parte, el amor gratuito y fiel genera vida, la despierta y la ayuda acrecer; y, por otra, la consideración de la originalidad de la vida del otro permite adaptarse para reconocer el lugar donde se encuentra y cooperar eficazmente a su crecimiento.

Será preciso entonces desprendernos de propios intereses para servir -desinteresadamente- al designio de Dios que sale a nuestro encuentro en nuestros hermanos. Esto requiere generosidad y habilidades específicas, que podemos llamar pedagógicas, pero en las cuales intervienen también otros aportes científicos y técnicos. A veces impresiona el desconocimiento de mínimas categorías psicológicas en nuestros planes y acciones pastorales (23). La incapacidad de conducir la vida adecuadamente -tan lejana a la acción de Cristo en el Evangelio- contribuye muchas veces sustancialmente al descrédito de la Iglesia y disminuye su credibilidad.

En este punto quiero dejar señalado otro ámbito de desafíos: aquellos que corresponden a la teología pastoral como disciplina, ya que sus limitaciones han afectado especialmente el carácter pedagógico de la acción pastoral de la Iglesia. Y quisiera mencionar especialmente la necesidad de mejorar el método teológico-pastoral. Aquí hay desafíos como: la percepción de la vida como lugar

(22) En este sentido se ha promovido el trabajo con "proyectos de vida", tanto para personas como para familias y comunidades. También se les llama "ideales", como por ejemplo en: Miguel Cabello, Manual de Planificación Pastoral. Santiago 1985. Pgs. 69 ss.

(23) Un ejemplo positivo de recepción de elementos pedagógicos es el nuevo manual de pastoral juvenil elaborado por el Celam. Cfr. Celam, Civilización del Amor, tarea y esperanza. Bogotá; 2000. Especialmente pgs. 181 ss. 
teológico, la precisión de formas de inducción e inferencia, la integración de otras ciencias (especialmente la psicología) en el diagnóstico pastoral, la superación del subjetivismo en la observación y el juicio, el carácter hipotético de las afirmaciones y los objetivos, la importancia de la evaluación y la autocrítica, el mejor conocimiento de las constantes que rigen los procesos vitales personales y comunitarios, etc. Un desarrollo adecuado de la reflexión teológico-pastoral ciertamente sería una contribución significativa a un acción pastoral más madura y a la credibilidad de la Iglesia.

Deberá mejorar, creemos, nuestra Iglesia su vida y su acción en los ámbitos de la comunidad, la comunicación, la misión y la celebración. Pero quiero terminar afirmando también estas últimas tres tesis en positivo, como se puede recoger de la experiencia:

1. La Iglesia gana credibilidad cuando es lugar de misericordia.

2. La Iglesia gana credibilidad cuando respeta (y ayuda a respetar) la dignidad.

3. La Iglesia gana credibilidad cuando tiene sentido pedagógico.

\section{RESUMEN}

La Iglesia existe para llevar a todos los hombres al encuentro vital con Jesucristo. Por eso es signo e instrumento de la salvación obrada por el Mesías (Cf. Lumen Gentium 9). Ahora bien, la pastoral busca hacer efectiva aquí y ahora, es decir, de modo histórico y situado esa capacidad de ser signo e instrumento de salvación. Aquí surge la importancia de la credibilidad de la Iglesia. Ella debe ser capaz de manifestar el misterio que porta a lo largo de la historia. Hoy nos encontramos con una fuerte crítica a la Iglesia justamente respecto a este aspecto central de su misión. El artículo mira cómo se está dando esa credibilidad en el Chile contemporáneo haciendo un análisis desde cuatro ámbitos pastorales centrales en la vida de la Iglesia: comunidad, comunicación, misión y celebración. Concluye planteando tres hipótesis de trabajo de orden pastoral: a) la Iglesia pierde credibilidad cuando no es lugar de misericordia; b) la Iglesia pierde credibilidad cuando no respeta la dignidad; c) la Iglesia pierde credibilidad cuando no tiene sentido pedagógico. Gana en credibilidad cuando supera estas tres falencias.

\section{ABSTRACT}

The reason of the existence of the Church is to lead all men to their vital encounter with Jesus. Hence it is sign and instrument of the salvation worked by The Messiah (Cf. Lumen Gentium 9). The role of the pastoral is to make effective her mission as sign and instrument of salvation, here and now, in a historical point of time and specific place. Here lies the importance of the credibility of the Church. She has to be able to manifest the mystery she bears all through history. Today the Church is subject of severe criticism to regarding this central aspect of her mission. The article discusses how that credibility is being developed in Chile these days, by analyzing four central pastoral aspects in the life of the Church: community, communication, mission and celebration. Finally, the article puts forward three hypotheses of work within the pastoral field: a) the Church loses credibility when it fails to be seen as a place of mercy; b) the Church loses credibility when the human dignity is not respected; c) the Church loses credibility when she lacks pedagogical sense. Conversely, the Church gains credibility when she overcomes these three shortcomings. 